\title{
miR-219-5p targets CaMKIIy to attenuate morphine tolerance in rats
}

\author{
Jian Wang ${ }^{1}$, Wei $\mathrm{Xu}^{1}$, Jiali Shao ${ }^{1}$, Zhenghua $\mathrm{He}^{1}$, Zhuofeng Ding ${ }^{1}$, Jiangju Huang ${ }^{1}$, \\ Qulian Guo ${ }^{1}$, Wangyuan Zou ${ }^{1}$ \\ ${ }^{1}$ Department of Anesthesiology, Xiangya Hospital, Central South University, Changsha, Hunan 410008, China
}

Correspondence to: Wangyuan Zou, email: wangyuanzou@hotmail.com

Keywords: morphine tolerance, microRNA, CaMKIIY, NMDA

Received: August 31, 2016

Accepted: February 27, 2017

Published: March 08, 2017

Copyright: Wang et al. This is an open-access article distributed under the terms of the Creative Commons Attribution License (CC-BY), which permits unrestricted use, distribution, and reproduction in any medium, provided the original author and source are credited.

\section{ABSTRACT}

Morphine tolerance is a clinical challenge in pain management. Emerging evidence suggests that microRNA (miRNA) plays a regulatory role in the development of morphine tolerance. miR-219-5p (miR-219) targets calmodulin-dependent protein kinase II Y (CaMKIIY) to activate central pain sensitization via $\mathrm{N}$-methyl-D-aspartate (NMDA) receptor. Therefore, we hypothesized that miR-219-5p attenuates morphine tolerance by targeting CaMKIIY. We found that the expression of miR-219-5p was decreased significantly after chronic morphine treatment. Overexpression of miR-219-5p by lentivirus injection prevents the development of morphine tolerance. CaMKIIY, the target gene of miR-219-5p was downregulated by overexpression of miR-219-5p both in vivo and in vitro. Furthermore, we found that lentiviral-mediated miR-219-5p decreased the expression of NMDA receptor subunit 1 (NR1), leading to attenuation of morphine tolerance. Overall, the data demonstrate that miR-219-5p plays a crucial role in alleviating morphine tolerance by inhibiting the CaMKII/NMDA receptor pathway. Overexpression of miR-219-5p may be a potential strategy to ameliorate morphine tolerance.

\section{INTRODUCTION}

Morphine is commonly used to alleviate moderateto-severe pain, especially cancer pain. Prolonged administration of morphine leads to morphine tolerance, which requires higher doses of morphine to produce the same analgesic effect [1]. The specific mechanism underlying morphine tolerance still remains unknown. Recent evidence suggests that post-translational regulation by miRNAs may mediate the development of morphine tolerance [2-4].

MicroRNAs (miRNAs) are small non-coding RNAs containing 18 22 nucleotides, which regulate gene expression at the translational level [5]. miRNAs repress mRNA expression or destabilize mRNA by binding to the 3'-untranslated region (UTR) of the target genes [6]. Currently, thousands of miRNAs have been identified in humans, and are involved in the pathophysiology of various diseases[7]. Evidence indicates that miRNA is expressed abundantly in nervous system and serves as an important epigenetic regulator of neurobiological activity, including neurogenesis, neuronal plasticity and pain perception [8-11]. Morphine tolerance is of growing interest in the study of miRNA-mediated cellular adaptation.

Several studies investigated the regulatory role of miRNA in the development of morphine tolerance. A few miRNAs attenuate morphine tolerance by regulating $\mu$-opioid receptor (MOR) expression. For example, Let-7 binds to 3'-UTR of MOR to repress its expression [12]. miR-23b acts as a trans-acting factor, which interacts with the $\mathrm{k}$ box motif of 3'-UTR of MOR1 to suppress MOR translation efficiency [13]. In addition to let-7 and miR$23 \mathrm{~b}$, other miRNAs involved in morphine tolerance include miR-124, miR-190, miR-103 and miR-93-5p [14-17]. In a previous study, we demonstrated the deregulation of nine different miRNAs in rat spinal cord after chronic morphine injection, including let-7, miR-365 and miR219-5p (miR-219)[4].Studies have demonstrated that miR219 regulates NMDA receptor-mediated neurobehavioral dysfunction and neuropathic pain by targeting calmodulindependent protein kinase II $\gamma(\mathrm{CaMKII} \gamma)[18,19]$.

Considering the importance of NMDA receptor in morphine tolerance [20], we hypothesized that miR-219$5 \mathrm{p}$ attenuates morphine tolerance by targeting CaMKII $\gamma$ in rats. 


\section{RESULTS}

\section{Downregulation of miR-219-5p expression in the spinal cord of morphine-tolerant rats}

After 7 consecutive days of intrathecal administration of morphine, the \% MPE of rats from chronic morphine treatment group (Mor group) was significantly decreased compared with the control group, indicating morphine tolerance model was successfully established (Figure 1A). Hargreaves test data also showed that morphine tolerance was established (Figure 1B). To investigate the possible link between miR-219-5p and morphine tolerance, we first analyzed the temporal changes in miR-219-5p expression of the spinal cord of rats using qRT-PCR. Compared with the control group, the data showed that miR-219-5p expression of Mor group declined on day 3 after morphine administration, to a minimum on day 7 (Figure 1C), correlating with the development of morphine tolerance (Figure 1A).

\section{Overexpression of miR-219-5p attenuates the development of morphine tolerance}

To examine the specific contribution of miR-219-5p to the development of morphine tolerance, a lentiviral vector-mediated miR-219-5p was intrathecally injected in rats. Green fluorescence was immunochemically detected in the spinal cord after injection of lentivirus, indicating lentivirus was successfully transfected (Figure 2A). Furthermore, qRT-PCR data showed upregulation in miR219-5p expression in the spinal cord, on the day 10 posttransfection (Figure 2B). The results indicated successful induction overexpression of miR-219-5p. We evaluated the effect of miR-219-5p overexpression on the development of morphine tolerance, intrathecal injection of the lentiviral miR-219-5p (LV-miR-219) and the negative control
(LV-NC) 3 days before consecutive saline or morphine injection in rats. Chronic morphine administration led to rapid and complete tolerance in rats treated with saline or LV-NC. However, in rats exposed to LV-miR-219, chronic morphine administration failed to induce morphine tolerance, and on day 7 after morphine administration, morphine still had antinociceptive effect, with a $70 \% \mathrm{MPE}$ (Figure 2C). These results suggested that overexpression of miR-219-5p prevented and attenuated the development of morphine tolerance. Moreover, the basal latencies of tail-flick tests were not significantly different between LV$\mathrm{NC}$ and LV-miR-219 group, indicating that overexpression of miR-219-5p did not have a direct analgesic effect (Figure 2D). We then investigated the effect of downregulation of miR-219 on morphine tolerance. We treated the rats with miR-219 sponge for 3 consecutive days to decrease the expression of miR-219-5p. We found that miR-219 sponge could attenuate the antinociceptive effect of morphine and produce thermal hyperalgesia in naive rats (Figure 2E, 2F). These data suggested miR-219-5p in the spinal cord contributes to the development of morphine tolerance.

\section{Overexpression of miR-219-5p decreased CaMKII $\gamma$ and NR1 expression in the PC12 cells}

To further explore the role of miR-219-5p in morphine tolerance, we investigated the relevant target genes. It was reported that miR-219-5p targeted CaMKII $\gamma$ to regulate NMDA receptor 1 (NR1) function [18]. Furthermore, both CaMKII family and NR1 were key regulators of morphine tolerance. Thus, we focused on CaMKII $\gamma$, a subtype of CaMKII family, for further study.

We investigated the effect of miR-219-5p overexpression on CaMKII $\gamma$ and NR1 by transfecting PC12 cells with LV-miR-219 and LV-NC. To confirm successful lentivirus delivery, cells were visualized
A

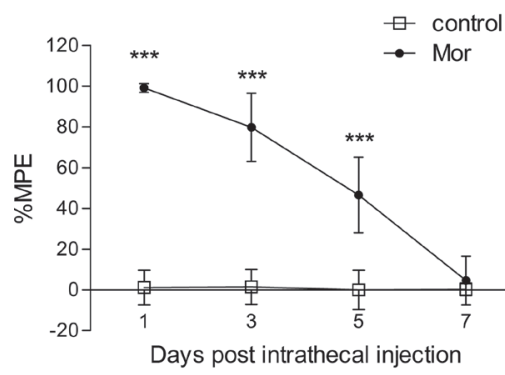

B

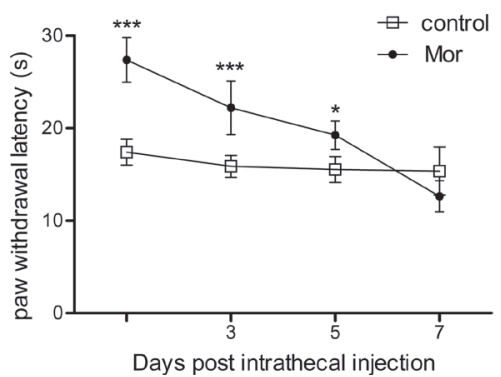

C

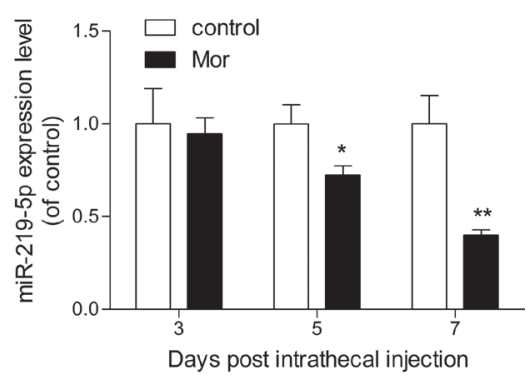

Figure 1: Chronic morphine treatment inhibits the expression of miR-219-5p. (A) Tail-flick test of morphine tolerance. Tail-flick test was performed at 1,3,5, and 7 days before or $30 \mathrm{~min}$ after morphine or saline injection. Tail-flick latency was converted to $\% \operatorname{MPE}(n=6, * * * P<0.001$, compared with control group, using two-way ANOVA followed by Bonferroni correction). (B) Thermal paw withdrawal latency test. Thermal paw withdrawal latency test was performed $30 \mathrm{~min}$ after morphine or saline injection. $(n=6, * P<0.05$, $* * * P<0.001$, compared with control group, using two-way ANOVA followed by Bonferroni correction). (C) Temporal changes in miR219-5p expression after chronic morphine treatment. The expression of miR-219-5p in L4 L5 spinal cord was examined at 3, 5, and 7 days after morphine or saline injection by qRT-PCR. Values were normalized to those of U6 before comparison $(n=4, * P<0.05, * * P<0.01$, compared with control group, by Student's $t$-test). All the data were expressed as mean \pm SD. Mor $=$ morphine $(10 \mu \mathrm{g} / 10 \mu \mathrm{L}$, twice daily) intrathecal injection for 7 days; control $=$ saline $(10 \mu \mathrm{L}$, twice daily) intrathecal injection for 7 days. 
A

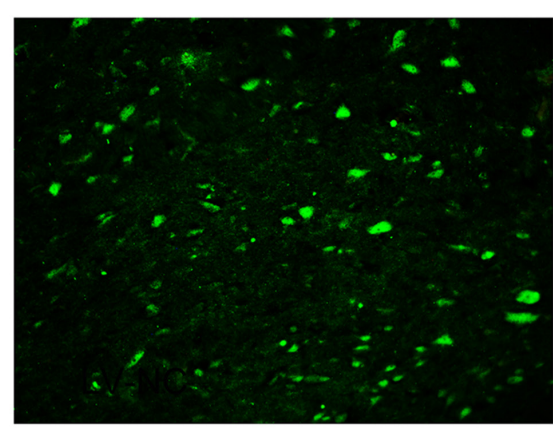

LV-NC+NS

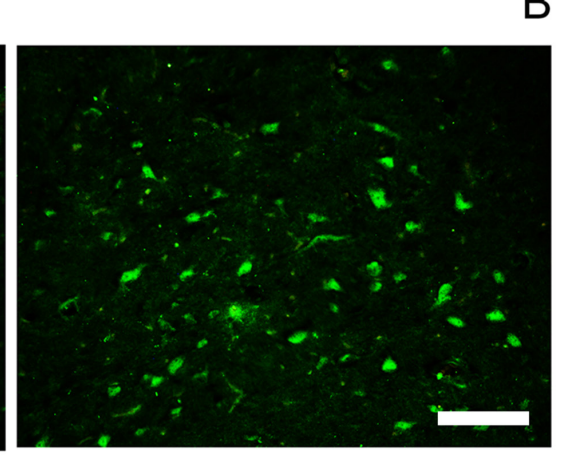

LV-miR-219+NS
C

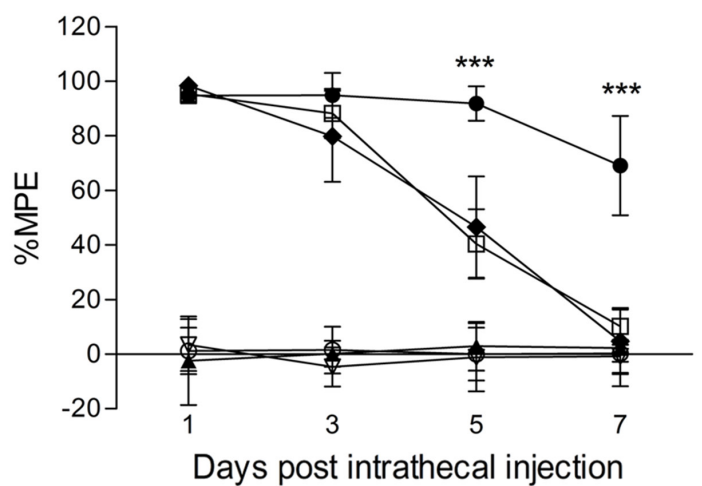

E

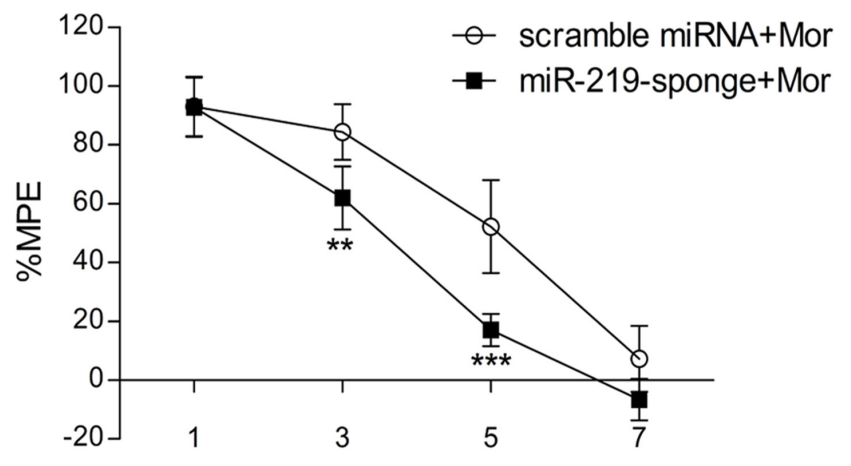

Days post intrathecal injection
B

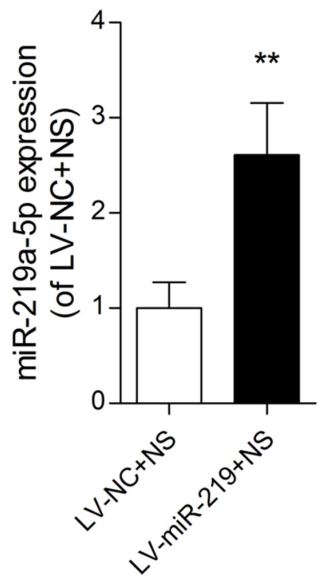

$\rightarrow$ control

$\neg$ Mor

- LV-miR-219+NS

$\rightarrow$ LV-miR-219+Mor

$\rightarrow$ LV-NC+NS

$\square$ LV-NC+Mor

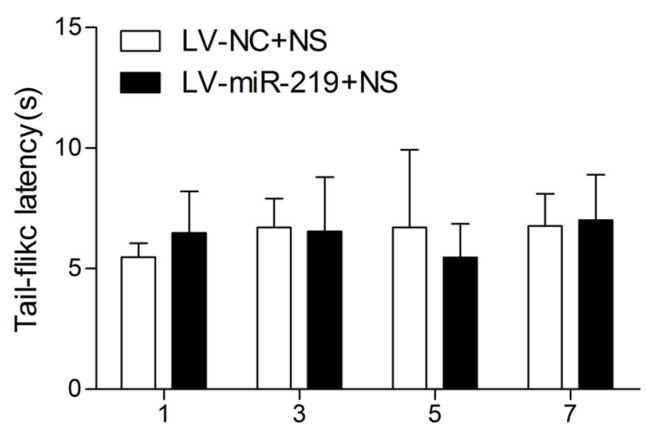

Days post intrathecal injection

F

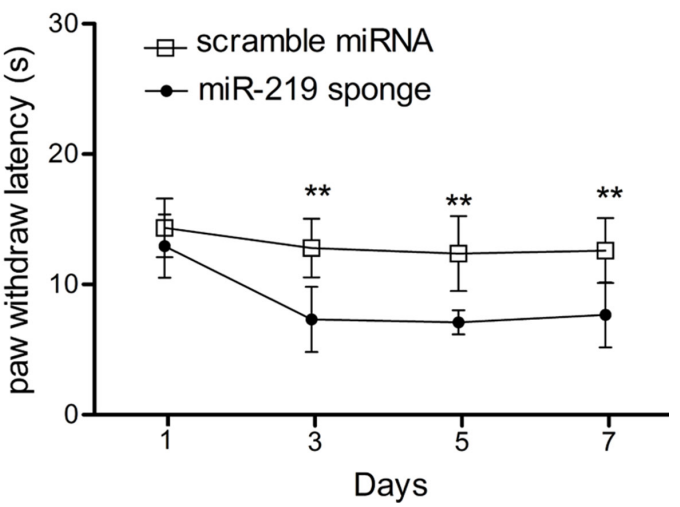

Figure 2: Overexpression of miR-219-5p attenuates the development of morphine tolerance. (A) Green fluorescent protein (GFP) was expressed in the lumbar spinal cord (L3 L4) 10 days after injection of LV-miR-219 and LV-NC followed by 7 days of intrathecal saline injection. Scale bar $=200 \mu \mathrm{m}$. (B) The expression of miR-219-5p was upregulated on the day 10 after lentivirus injection. Rats were injected with LV-miR-219 and LV-NC, 3 days before normal saline infusion $(n=4, * * P<0.01$, compared with LV-NC+NS, by Student's $t$-test). (C) Overexpression of miR-219-5p attenuated the development of morphine tolerance. $(n=6$, *** $P<0.001$, compared with LV$\mathrm{NC}+$ Mor, by two-way ANOVA followed by Bonferroni correction); Mor $=$ morphine $(10 \mu \mathrm{g} / 10 \mu \mathrm{L}$, twice daily) intrathecal injection for 7 days; control $=$ saline $(10 \mu \mathrm{L}$, twice daily $)$ intrathecal injection for 7 days; LV-miR-219+NS/Mor = intrathecal injection with LV-miR-219 3 days before consecutive normal saline/morphine infusion; LV-NC+NS/Mor = intrathecal injection with LV-NC 3 days before consecutive normal saline/morphine infusion. (D) Basal tail-flick latency remained unchanged after overexpression of miR-219-5p. Basal tail-flick latencies were recorded on days $1,3,5$, and 7 after morphine or saline infusion $(n=6)$. (E) Effect of miR-219 sponge on the development of morphine tolerance. $(n=5, * * P<0.01, * * * P<0.001$, compared with scramble miRNA + Mor group, using two-way ANOVA followed by Bonferroni correction); scramble miRNA/miR-219-sponge+Mor = intrathecal injection with scramble miRNA or miR-219-sponge for 3 consecutive days after morphine infusion. (F) Effect of miR-219 sponge on the paw thermal threshold of naive rats. $(n=5$, $* * P<0.01$, compared with scramble miRNA group, using two-way ANOVA followed by Bonferroni correction); scramble miRNA/miR-219 sponge = intrathecal injection of scramble miRNA or miR-219 sponge daily for 3 consecutive days on naive rats. All the data were expressed as mean \pm SD. 
microscopically to detect GFP fluorescence (Figure 3A). The qRT-PCR data showed that the expression of miR219-5p was significantly increased in LV-miR-219-treated cells compared with LV-NC cells (Figure 3B). The Western blot data showed that LV-miR-219 treatment dramatically decreased the protein levels of both CaMKII $\gamma$ and NR1 (Figure 3C). These results were consistent with previous studies $[18,19]$, indicating that CaMKII $\gamma$ was the target of miR-219-5p and overexpression of miR-219-5p decreased CaMKII $\gamma$ and NR1 expression in the PC12 cells.

\section{miR-219-5p targets CaMKII $\gamma$ to alleviate morphine tolerance}

To gain further insight into the mechanism of miR-219-5p in morphine tolerance, we investigated the expression of CaMKII $\gamma$ in the context of morphine tolerance. Western blot showed that CaMKII $\gamma$ was gradually increased after intrathecal injection of morphine (Figure 4A). And we found that knockdown of spinal CaMKII $\gamma$ by siRNA intrathecal injection restored the antinociceptive effect of morphine (Figure 4B), suggesting knockdown of CaMKII $\gamma$ could attenuate morphine tolerance. To further explore the interaction between miR-219-5p and CaMKII $\gamma$ in morphine tolerance, we first examined whether overexpression of miR-219-5p affected CaMKII $\gamma$ expression. Overexpression of miR219-5p reversed the increased expression of CaMKII $\gamma$ by intrathecal injection of LV-miR-219 rather than LV-NC (Figure 4C). Immunochemistry results were consistent with Western blot results (Figure 4D). Then we investigated the effect of downregulation of miR-219-5p on the expression of CaMKII $\gamma$, we found downregulation of miR-219-5p by miR-219 sponge increased the expression of CaMKII $\gamma$ (Figure 4E). Moreover, intrathecal injection of CaMKII $\gamma$ siRNA partially abolished miR219 sponge induced decline of \%MPE after morphine injection (Figure 4F, 4G). Therefore, these data suggested that overexpression of miR-219-5p alleviated morphine tolerance by targeting CaMKII $\gamma$.

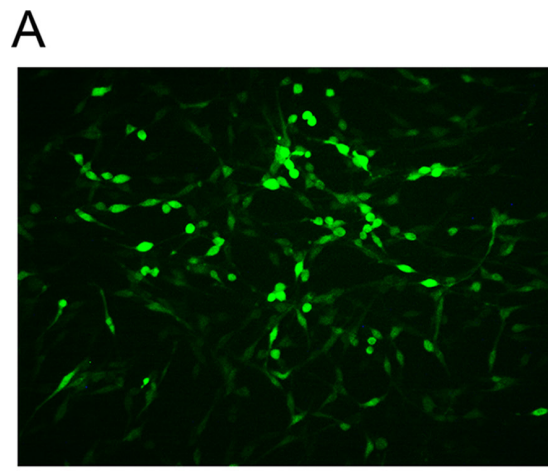

LV-NC

C

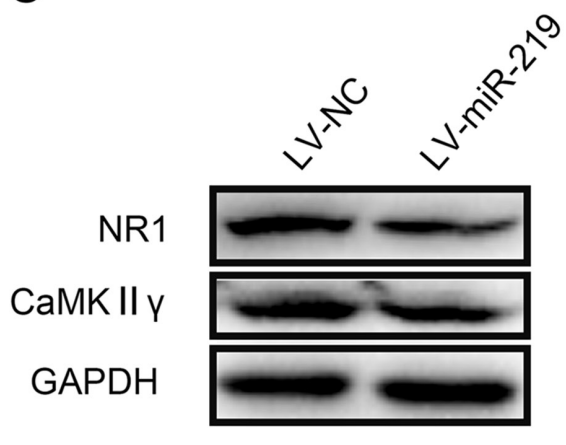

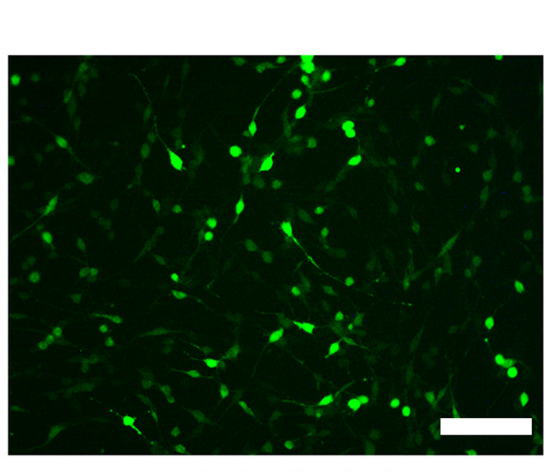

LV-miR-219

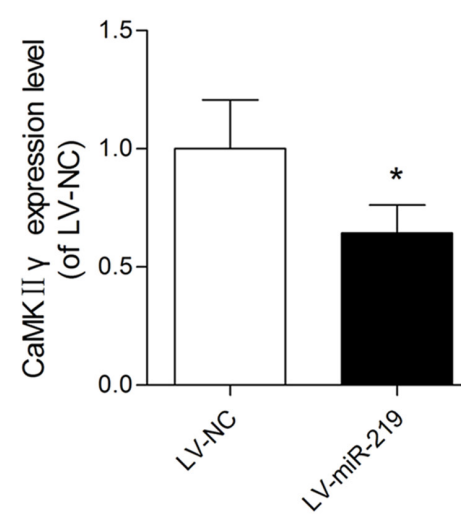

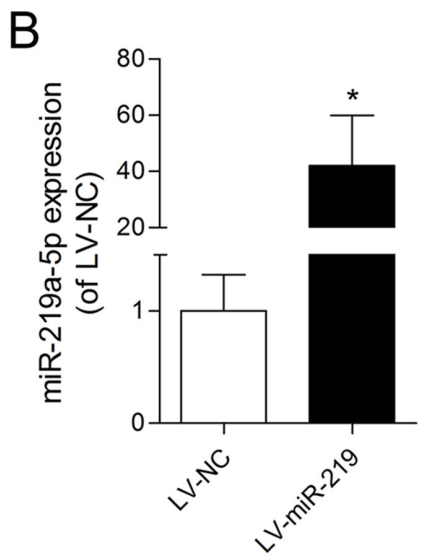

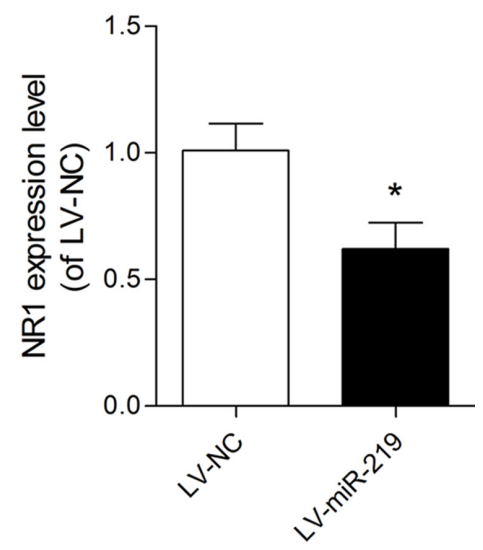

Figure 3: Overexpression of miR-219-5p decreased CaMKII $\gamma$ and NR1 expression in PC12 cells. (A) GFP was visualized in PC12 cells after transfection with lentiviral miR-219-5p (LV-miR-219) and lentiviral negative control (LV-NC), Scale bar $=100 \mu \mathrm{m}$. (B) Expression of miR-219-5p was examined by qRT-PCR in PC12 cells, 5 days after lentivirus infection. LV-miR-219 induced robust upregulation of miR-219-5p expression in PC12 cell $(n=3, * P<0.05$, compared with LV-NC group, by Student's $t$-test). (C) Western blots showed the protein expression of CaMKII $\gamma$ and NR1 in PC12 cells after lentivirus infection. GAPDH was used as loading control. The expression of CaMKII $\gamma$ and NR1 was downregulated after PC12 cells were transfected with LV-miR-219 $(n=4, * P<0.05$, compared with LV-NC group, by Student's $t$-test). All the data were expressed as mean $\pm \mathrm{SD}$. 


\section{NMDAR1 is involved in miR-219 mediated regulation of morphine tolerance}

Our study found that miR-219-5p targeted CaMKII $\gamma$ to regulate morphine tolerance. However the specific mechanism under this process was not clear. A recent study revealed that CaMKII $\gamma$ was a downstream target in the NMDA signaling pathway, which modulated NMDAR trafficking [18, 21]. Our in vitro results showed that overexpression of miR-219-5p repressed the expression of NR1 in PC12 cells (Figure 3C). Moreover, it has been demonstrated that blocking NMDA receptor function attenuates morphine tolerance $[22,23]$. Thus,

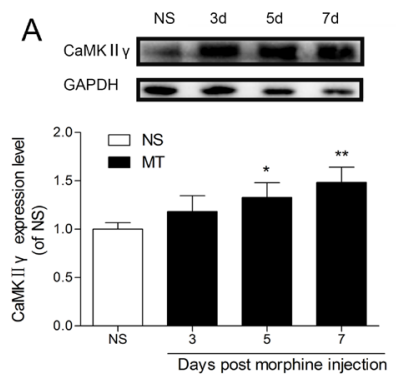

E

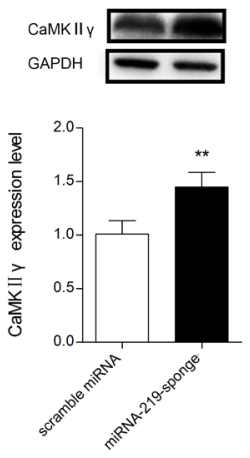

B

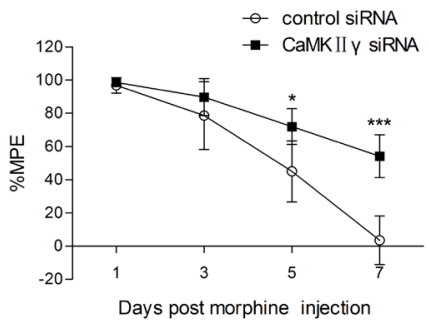

$\mathrm{F}$

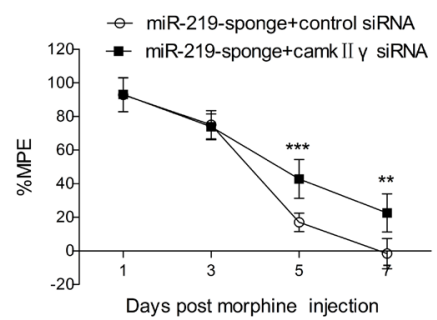

we hypothesized that miR-219-5p target CaMKII $\gamma$ to regulate NMDAR1 (NR1) function in morphine tolerance. To test the hypothesis, we first examined the localization of CaMKII $\gamma$ and NR1 in the spinal cord. Double immunofluorescence labeling revealed that NR1 was co-expressed with CaMKII $\gamma$ in the dorsal horn of spinal cord (Figure 5), indicating that CaMKII $\gamma$ may interact with NR1 spatially. We next investigated the expression changes in NR1 after chronic morphine injection. We found that NR1 expression was gradually increased after morphine injection (Figure 6A), which was consistent with the changes in CaMKII $\gamma$ (Figure 4A), and increased NR1 expression was downregulated by the overexpression
C

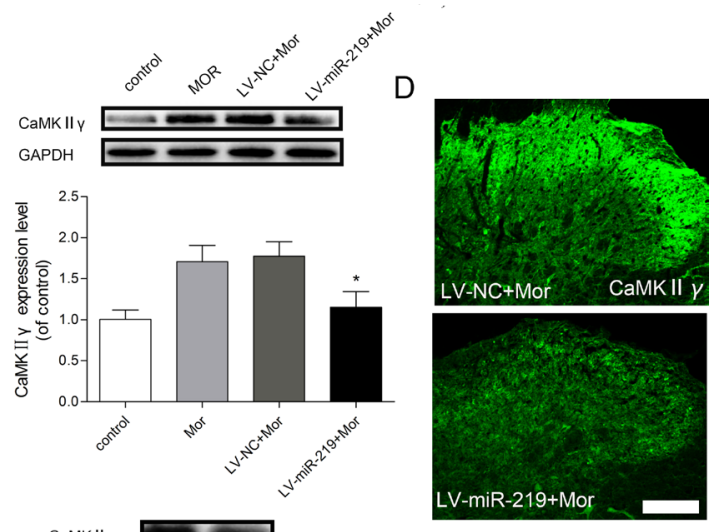

G

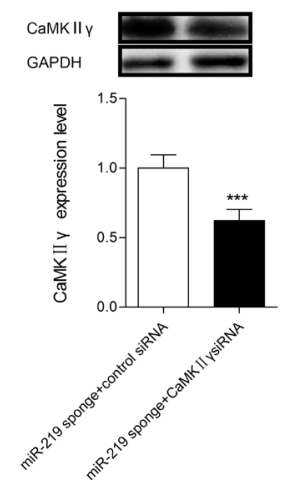

Figure 4: CaMKII $\gamma$ is responsible for miR-219-5p induced attenuation of morphine tolerance. (A) Time course of CaMKII $\gamma$ changes in L4 L5 spinal cord during the development of morphine tolerance. Western blot of CaMKII $\gamma$ expression in the spinal cords of rats treated with saline infusion (NS) on the day 7, and in the morphine infusion group (MT) on days 3, 5, and 7. GAPDH was used as loading control $(n=3, * P<0.05$, compared with NS group, by one-way ANOVA followed by Bonferroni test). (B) CaMKII $\gamma$ siRNA attenuates the development of morphine tolerance. CaMKII $\gamma$ siRNA and control siRNA were intrathecally injected daily for 3 consecutive days after morphine infusion. $\left(n=5,{ }^{*} P<0.05,{ }^{*} * P<0.001\right.$, compared with control siRNA group, using two-way ANOVA followed by Bonferroni correction). (C) Expression of CaMKII $\gamma$ protein in the spinal cord 10 days after lentivirus injection. The increased expression of CaMKII $\gamma$ induced by chronic morphine treatment was reduced by overexpression of miR-219-5p ( $\mathrm{n}=3,{ }^{*} P<0.05$, compared with LVmiR-219+Mor, by one-way ANOVA followed by Bonferroni test). Control = saline (10 $\mu \mathrm{L}$, twice daily) intrathecal injection for 7 days; Mor $=$ Morphine $(10 \mu \mathrm{g} / 10 \mu \mathrm{L}$, twice daily $)$ intrathecal injection for 7 days; LV-miR-219/LV-NC+Mor $=$ LV-miR-219 or LV-NC $(10 \mu \mathrm{L})$ plus 7 days morphine infusion ( $10 \mu \mathrm{g} / 10 \mu \mathrm{L}$, twice daily). (D) Representative images of CaMKII $\gamma$ in the spinal cord by immunofluorescent labeling 10 days after lentivirus injection followed by consecutive morphine infusion. Scale bar $=100 \mu \mathrm{m}$. (E) Expression of CaMKII $\gamma$ protein in the spinal cord of naive rats on the day 7 after scramble miRNA or miRNA-219-sponge intrathecal injection. $\left(n=4,{ }^{* *} P<0.01\right.$, compared with scramble miRNA group, by Student's $t$-test). (F) CaMKII $\gamma$ siRNA partially restore the loss of antinociceptive effect of morphine induced by miR-219 sponge. $\left(n=5, * * P<0.01,{ }^{* * *} P<0.001\right.$, compared with miR-219 sponge + control siRNA group, using two-way ANOVA followed by Bonferroni correction); miR-219 sponge + CaMKII $\gamma$ siRNA/control siRNA = miR-219 sponge was intrathecally injected for 3 days after consecutive morphine infusion, CaMKII $\gamma$ siRNA or control siRNA was intrathecally injected for 3 consecutive days from day 4 after morphine injection. (G) Expression of CaMKII $\gamma$ protein in the spinal cord on the day 7 after injection of miR-219 sponge and CaMKII $\gamma$ siRNA in morphine treated rats. $(n=4, * * * P<0.001$, compared with miR-219 sponge+control siRNA group, by Student's $t$-test). All the data were expressed as mean $\pm \mathrm{SD}$. 
of miR-219-5p accompanied with downregulation of CaMKII $\gamma$ (Figure 6B, 6C). Moreover, we found the expression of NR1 was also upregulated in rats receiving miR-219 sponge (Figure 6D), and knockdown of CaMKII $\gamma$ by siRNA could block this effect (Figure 6E). Together, these results suggested that NR1 is involved in miR-219 mediated regulation of morphine tolerance.

\section{DISCUSSION}

miRNAs regulate multiple neurological mechanisms. Our data support the role of miR-219-5p in attenuating morphine tolerance. In the present study, we investigated the dynamic changes in miR-219-5p and CaMKII $\gamma$ using the morphine tolerance model. We found that consecutive intrathecal administration of morphine decreased the expression of miR-219-5p in the spinal cord, and increased the expression of CaMKII $\gamma$. We also demonstrated that intrathecal administration of LV-miR-219 prevented the development of morphine tolerance and in turn decreased the expression of CaMKII $\gamma$. Moreover, we found that NMDA receptor subunit NR1 was regulated by CaMKII $\gamma$ and involved in
miR-219-5p mediated attenuation of morphine tolerance. Our findings indicate that miR-219-5p may represent a novel treatment for morphine tolerance.

miR-219-5p was previously recognized as a brainspecific miRNA that was only expressed in the brain [24]. It was found to mediate various neuronal processes, such as cell proliferation, differentiation and myelin maintenance $[25,26]$. miR-219-5p is deregulated in neuronal dysfunction. Previous studies reported that miR219 was highly upregulated in the brain of schizophrenia patients [27], and downregulated in subventricular zone and hippocampus of mice with amyotrophic lateral sclerosis (ALS)[28]. Recent studies suggest that miR-219 was also involved in the pathophysiology of Alzheimer's disease (AD) and epilepsy [21, 29].

Our study found that chronic administration of morphine significantly down-regulated the expression of miR-219-5p. This study firstly described the altered expression of spinal miR-219-5p in morphine tolerance. After intrathecal administration of lentivirus, we found that the overexpression of miR-219-5p significantly alleviated morphine tolerance. However, the anti-nociceptive effect of morphine was not fully restored by LV-miR-219, suggesting the possible role of other miRNAs or unknown
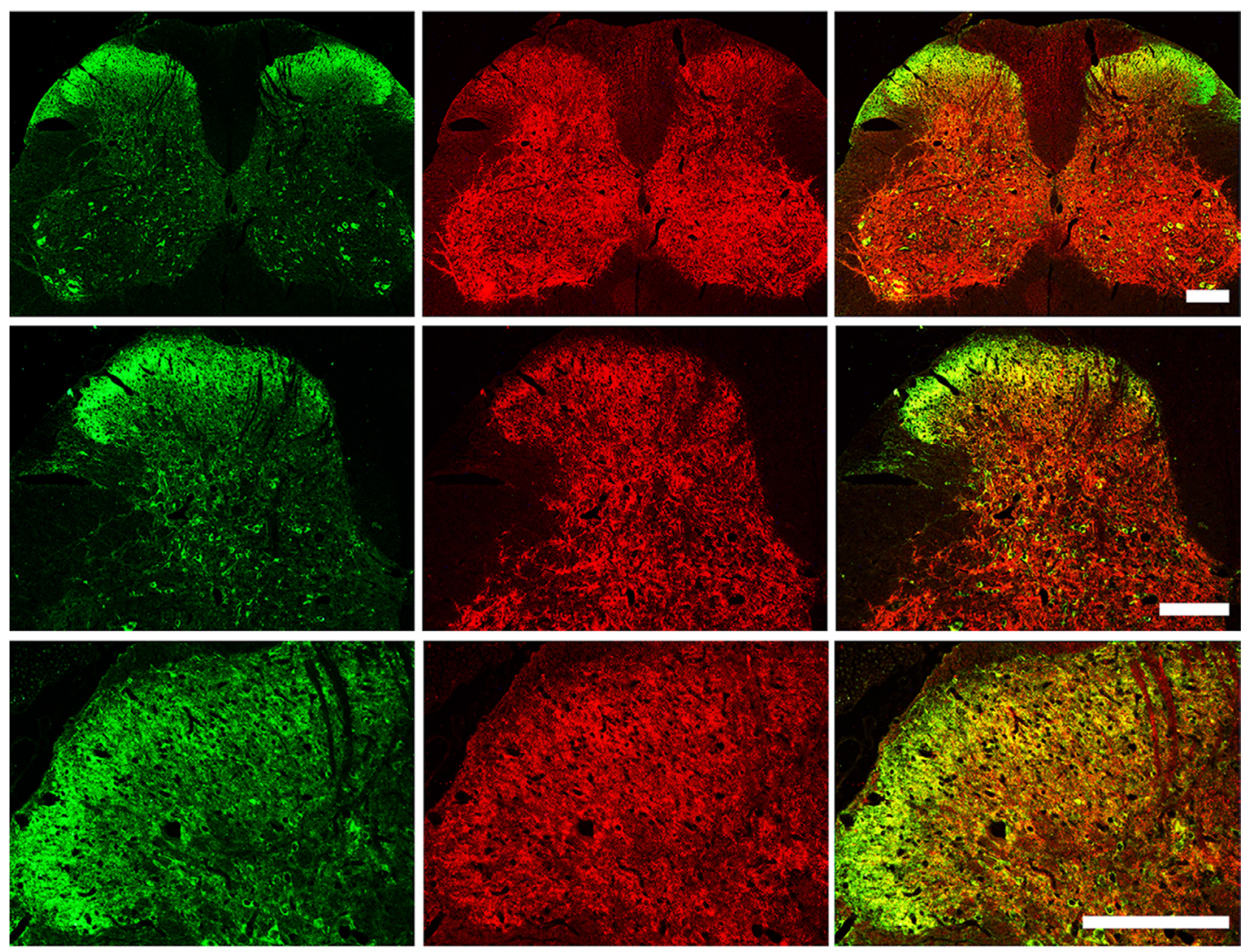

CaMK II y

NR1

Merge

Figure 5: Localization of CaMKII $\gamma$ and NR1 in the spinal cord. Double immunofluorescence labeling showing abundant expression of both CaMKII $\gamma$ (green) and NR1 (red), and co-expression of CaMKII $\gamma$ and NR1(yellow) in the spinal cord under different levels of magnification. Scale bar $=200 \mu \mathrm{m}$. 
mechanisms. Consistent with previous study, we also found blocking miR-219-5p induced thermal hyperalgesia, indicating its potential role in pain management [19].

miRNA mostly regulates the target gene expression negatively. There are some studies have reported that miR-219-5p directly targets CaMKII $\gamma[18,19]$.Therefore, CaMKII $\gamma$, a target gene of miR-219-5p was selected for further study. CaMKII $\gamma$ is a component of CaMKII enzyme family. CaMKII activation depends on $\mathrm{Ca}^{2+}$ / calmodulin, and is a multifunctional protein kinase highly expressed in CNS. Activation of CaMKII in CNS has been shown to play a crucial role in gene expression, memory processing, learning and neuroplasticity [30-32]. The specific role of CaMKII in morphine tolerance was inconsistent. Lou et al. [33] found that the subtype of CaMKII was expressed differentially following acute and chronic morphine treatment. Acute morphine treatment increased CaMKII activity in rat hippocampus, with little alteration in protein levels. Chronic morphine treatment down-regulated CaMKII activity, and increased the protein

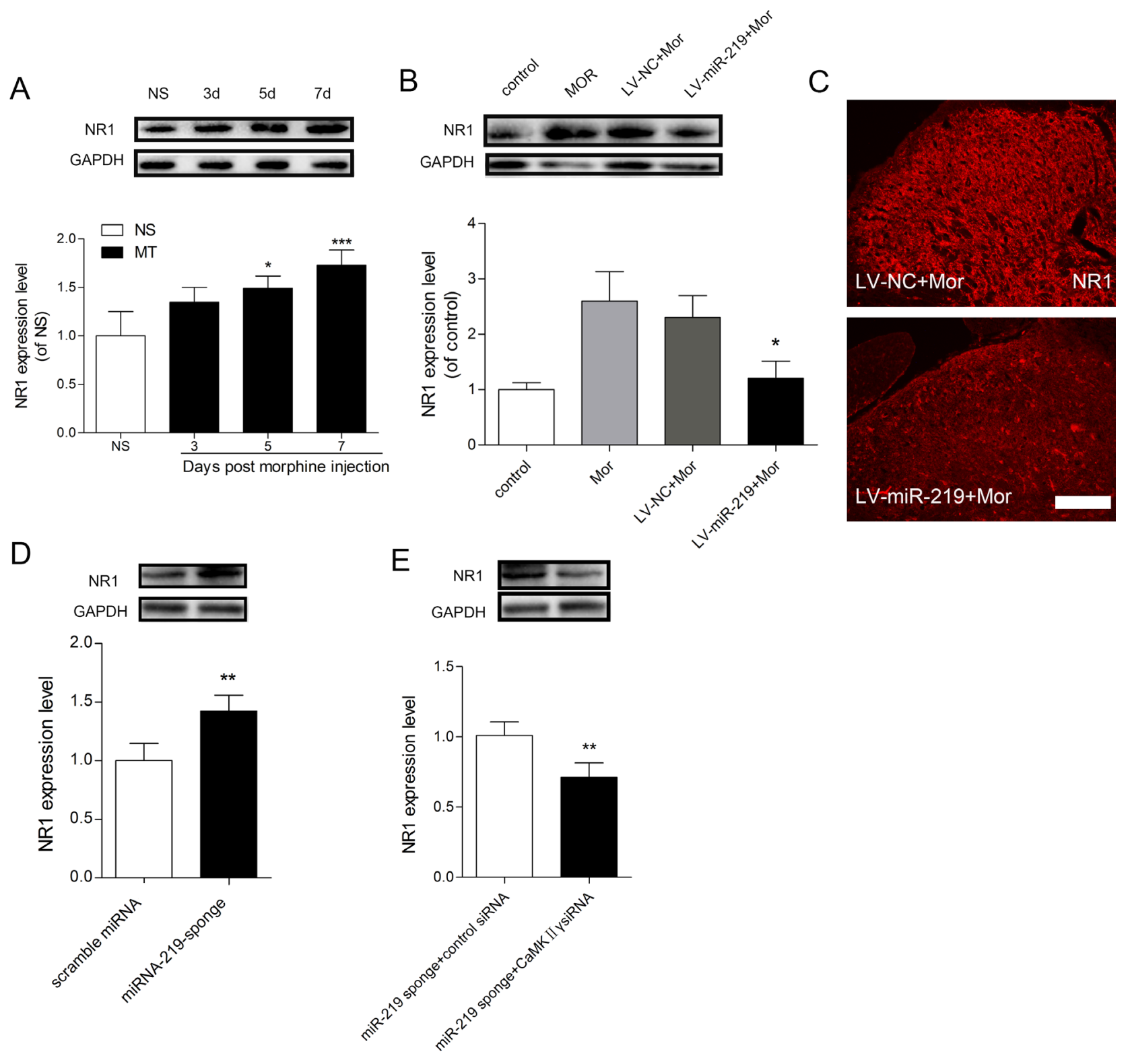

Figure 6: NR1 is involved in miR-219-5p mediated regulation of morphine tolerance. (A) Western blot analysis of changes in NR1 expression of the spinal cord (L4 L5) during morphine tolerance. GAPDH was used as a loading control $(n=3, * P<0.05$, compared with NS group, by one-way ANOVA followed by Bonferroni test). (B) miR-219-5p overexpression reduced NR1 expression in the spinal cord after chronic morphine treatment $\left(n=3,{ }^{*} P<0.05\right.$, compared with LV-miR-219+Mor, by one-way ANOVA followed by Bonferroni test). (C) Representative image of NR1 expression in spinal cord 10 days after lentivirus injection Scale bar $=100 \mu \mathrm{m}$. (D) Expression of NR1 protein in the spinal cord of naive rats on the day 7 after scramble miRNA or miRNA-219-sponge injection. $(n=4$, $* * P<0.01$, compared with scramble miRNA group, by Student's $t$-test). (E) Expression of NR1 protein in the spinal cord on the day 7 after injection of miR-219 sponge and CaMKII $\gamma$ siRNA in morphine treated rats. $\left(n=4,{ }^{*} P<0.001\right.$, compared with miR-219 sponge + control siRNA group, by Student's $t$-test). All the data were expressed as mean $\pm \mathrm{SD}$. 
levels of $\beta$ isoform of CaMKII, with little effect on $\alpha$ isoform. Fan et al. [34] reported that down-regulation or inhibition of CaMKII strongly attenuated morphine tolerance and dependence. Repeated morphine treatment increased the expression of both $\alpha$ and $\beta$ isoforms as well as CaMKII activity via induction of morphine sensitization [35].

However, the effect of morphine tolerance on the expression of CaMKII $\gamma$ in the spinal cord is unclear. In our study, we found that CaMKII $\gamma$ expression in the spinal cord was gradually upregulated after chronic morphine treatment, which was negatively correlated with changes in miR-219-5p expression. After overexpression of miR-219-5p, the increased expression of CaMKII $\gamma$ induced by chronic morphine exposure was significantly downregulated with attenuation of morphine tolerance, indicating that targets CaMKII $\gamma$ to regulate morphine tolerance. Our in vitro test also demonstrated that overexpression of miR-219-5p inhibited CaMKII $\gamma$ expression.

CaMKII $\gamma$ is involved in NMDAR-mediated neuroplasticity and psychiatric dysfunction [18]. CaMKII $\gamma$ is an integral downstream target in NMDA-mediated $\mathrm{Ca}^{2+}$ signaling and negatively regulates the expression of NMDAR1 to alleviate CFA-induced chronic inflammatory pain $[18,19]$. NMDA receptor, which belongs to glutamatergic receptor system, plays an important role in central sensitization and neuronal plasticity [36, 37]. NMDA receptor is comprised of NR1, NR2A-D and NR3 subunits. Activation of NMDA receptor has been reported to play a crucial role in the development of morphine tolerance [38]. Chronic morphine treatment altered NMDA receptor expression and up-regulated the expression of NR1 [39]. Inhibition of NMDA receptor activity by its noncompetitive antagonist MK801 or NR1 antisense oligonucleotide alleviated morphine tolerance $[22,40]$. Our current study showed that chronic morphine treatment was associated with a time-dependent upregulation of NR1 subunit in the spinal cord, which was consistent with a previous report [41]. Furthermore, our study demonstrated that NR1 expression was correlated with the expression of miR-219-5p. The expression of NR1 was downregulated after injection of miR-219$5 \mathrm{p}$, and upregulated after injection of miR-219 sponge. Because NR1 was not the target gene of miR-219-5p, the expression change of NR1 following miR-219 disturbance may result from the changes of CaMKII $\gamma$.

Consistent with our findings, Hu et al. [42] found that miR-219 in dorsal root ganglion (DRG) contributed to morphine tolerance by targeting CaMKII $\gamma$ to regulate brain-derived neurotrophic factor (BDNF) expression. Growing evidences suggested BDNF is involved in spinal plasticity and central sensitization and NR1 activation is enhanced by BDNF released both in the spinal cord and DRG $[43,44]$. BDNF is produced by microglia or neuron, and through presynaptic receptor signal transduction pathways to promote glutamate release, at the same time,
BDNF acts on the AMPA and enhanced NMDA activity by postsynaptic receptor pathway, and participates in and promote LTP [45-47]. Thus we cannot deny the possibility that BDNF may act as a mediator in miR-219-CaMKII $\gamma$ NR1 pathway in the study. Further study is still needed to clarify the specific role of BDNF in miR-219 mediated regulation of morphine tolerance in the spinal cord.

In addition to CaMKII $\gamma$, several other target genes of miR-219-5p have been studied. It has been reported that miR-219-5p targets EGFR to inhibit glioma cell proliferation and migration [48]. miR-219$5 \mathrm{p}$ also targets oncogene Sall4 to suppress colon cancer proliferation and invasion [49]. Santa-Maria et al. [29] reported that dysregulation of microRNA-219 promotes neurodegeneration through post-transcriptional regulation of tau. However, none of these target genes are related to morphine tolerance. As miR-219-5p has hundreds of target genes, we cannot exclude the possibility that other target genes are involved in the context of morphine tolerance.

Based on our experiments, our findings can be summarized as follows: chronic morphine treatment downregulates expression of miR-219-5p, which upregulates the expression of CaMKII $\gamma$. Upregulation of CaMKII $\gamma$ increases NMDA receptor expression and activity, resulting in morphine tolerance. Overexpression of miR-219-5p silences the translation of CaMKII $\gamma$, and inhibits expression of NR1, resulting in alleviation of morphine tolerance. However, our study is associated with a few limitations. Neither miR-219-5p mimic nor lentiviral-mediated overexpression increased the expression of miRNA to an appropriate level for optimal function with minimal side effects. Further studies are still needed to elucidate the precise mechanisms and potential side effects of miR-219-5p involved in attenuating morphine tolerance, and investigate other target genes of miR-219-5p in the context of morphine tolerance.

In conclusion, our results show that miR-219-5p is involved in morphine tolerance by targeting CaMKII $\gamma$ and then affects NR1 expression. Increasing miR-219-5p expression level by intrathecal administration of lentivirusmediated miR-219-5p attenuates morphine tolerance and decreases CaMKII $\gamma$ and NR1 expression. Our study expands our knowledge of the functional role of miR-219-5p and provides a novel and promising strategy for the treatment of morphine tolerance.

\section{MATERIALS AND METHODS}

\section{Animals}

Male Sprague-Dawley rats, each weighing $220 \mathrm{~g}$ to $250 \mathrm{~g}$ (Experimental Animal Center of Central South University) were housed in plastic cages under a 12 -h light/12-h dark cycle. Food and water were provided ad libitum. All the procedures were consistent with the guidelines approved by the Administrative Committee 
of Experimental Animal Care and Use of Central South University. The study was compliant with the Ethical Guidelines of the International Association for the Study of Pain [50]. Efforts were made to minimize the number of animals and all the behavioral tests were performed by an observer blinded to animal treatment.

\section{Induction of morphine tolerance}

Intrathecal catheter implantation was performed according to the methods of Yaksh [51]. Briefly, a PE10 catheter was inserted through a cistemal incision and advanced caudally into the subarachnoid space of lumbar enlargement (L3 L4). After catheter implantation, rats were allowed to recover for 3 days, and any rat with paralysis or motor weakness was excluded from the experiment. To induce morphine tolerance, $10 \mu \mathrm{g}$ morphine sulfate (in a volume of $10 \mu \mathrm{L}$ ) was delivered via an intrathecal catheter twice daily for $7 \mathrm{~d}$. The control group was injected with $10 \mu \mathrm{L}$ normal saline. Injections were followed by administration of $10 \mu \mathrm{L}$ normal saline to flush the catheter [52]. Morphine analgesia was assessed on the test day using the tail-flick test both before and 30 min after morphine administration.

\section{Tail-flick test}

The tail-flick test using radiant heat was performed to assess morphine analgesia among the different groups as previously described [53]. The intensity of the heat source was adjusted to ensure a basal latency of $4 \sim 6 \mathrm{sec}$, and a cut-off latency of $15 \mathrm{sec}$ was set to minimize tissue damage. Tail-flick test was performed both before (baseline latency) and $30 \mathrm{~min}$ after morphine administration. The results were converted to the maximal possible anti-nociceptive effect ( $\% \mathrm{MPE})$. The $\%$ MPE was calculated as follows: \% MPE $=[$ (postdrug latencies-baseline latencies)/(cutoff time-baseline latencies)] $\times 100$.

\section{Hargreaves thermal withdrawal latency test}

Thermal paw withdrawal latency test was performed by a Hargreaves apparatus (Plantar test, 7370; Ugo Basile, Comerio, Italy) as previously described $[54,55]$. For this measurement, rats were placed on a glass platform within transparent plastic cylinders. After 15 min of acclimation, a heat beam was focused on the plantar surface of one hind paw. Withdrawal latency of the hind paw from the heat source was recorded as the response latency. A $25 \mathrm{sec}$ cutoff was set to prevent tissue damage. Three measurements were made with an interval of $5 \mathrm{~min}$.

\section{PC-12 cell culture}

Differenced PC-12 cells were maintained in RPMI 1640 media (Invitrogen) containing 10\% fetal bovine serum (FBS) (Gibco), 50 units/mL of penicillin and $50 \mu \mathrm{g} /$ $\mathrm{mL}$ streptomycin in a humidified atmosphere of $5 \% \mathrm{CO}_{2}$ at $37^{\circ} \mathrm{C}$. The cells were passed every two days.

\section{Lentiviral system}

Lentiviral vector-mediated miR-219-5p (LV-miR-219) was purchased from Genepharma. The titer of lentivirus was $2 \times 10^{9} \mathrm{TU} / \mathrm{ml}$. The sequence of miR-219-5p was designed as follows: TGATTGTCCAAACGCAATTCT and cloned into pGLV3/H1/GFP+Puro vector. Scrambled oligonucleotides (TTCTCCGAACGTGTCACGT) were used as negative control (LV-NC). PC-12 cells were transfected with lentivirus at $100 \mathrm{MOI}$ for $24 \mathrm{~h}$, for the in vitro test. In vivo, LV-miR-219 was intrathecally injected via catheter 3 days before the induction of morphine tolerance. The GFP fluorescence in the PC-12 cells and spinal cord was monitored to confirm successful transfection, using a fluorescent microscope (Leica, Germany).

\section{miRNA sponge and siRNA}

miR-219 sponge, scramble miRNA, CaMKII $\gamma$ siRNA and control siRNA were purchased from Genepharma. The target sequence of miR-219 sponge was designed as following: AGAATTGCGTTTGGACAATCA. For naive rats, miR-219 sponge $(20 \mu \mathrm{g}, 4 \mu \mathrm{L})$ and scramble miRNA was intrathecal injected daily for 3 consecutive days, for rats receiving continuous morphine, they were intrathecal injected for 3 consecutive days just after morphine injection. CaMKII $\gamma$ siRNA (sense 5'-GGAUAUGCCGACUUCUGAATT-3', antisense 5'-UUCAGAAGUCGGGCAUAUCCTT-3') (40 $\mu \mathrm{M}$, $4 \mu \mathrm{L}$ ) and control siRNA were also intrathecal injected for 3 consecutive days after morphine or miR-219 sponge injection.

\section{Quantitative real-time PCR (qRT-PCR)}

Total RNA from the lumbar spinal cord (L4 L5) or PC-12 cell was isolated with TRIzol (Invitrogen) according to the manufacturer's recommendations. Following DNase digestion, RNA quantity and quality was determined by Nanodrop 2000 (Thermo Scientific). RNAs were reverse transcribed using TaqMan microRNA Reverse Transcription kit (Applied Biosystems) according to the manufacturer's protocol. The qRT-PCR was performed using specific primers for miR-219-5p (GSP: 5'GGTGA TTGTCCAAACGG3' R: 5'CAGTGCGTGTCGTGGA3') in an ABI prism 7900HT system (Applied Biosystems) with Fast Start Universal SYBR Green Master (Rox) (Roche). U6 (F: 5'GCTTCGGCAGCACATATACTAAAAT3' R: 5'CGCTTCACGAATTTGCGTGTCAT3') was used for normalization. The qRT-PCR conditions were: $95^{\circ} \mathrm{C}$ 
for $10 \mathrm{~min}, 40$ cycles of $95^{\circ} \mathrm{C}$ for $10 \mathrm{sec}$, and $60^{\circ} \mathrm{C}$ for $60 \mathrm{sec}$. All the samples were run in duplicate. The relative expression of miRNA was determined using the $2^{\text {(-ddCt) }}$ calculations [56], and expressed as fold change of control sample.

\section{Immunochemistry}

Rats were transcardially perfused with 4\% paraformaldehyde. The spinal cord in the lumbar enlargement was resected and post-fixed for $2 \mathrm{~h}$ before transfer to $25 \%$ PBS-sucrose overnight. After dehydration, the spinal cord was embedded with TissueTek O.C.T compound (Sakura) and 10- $\mu \mathrm{m}$-thick frozen sections were obtained. For immunochemistry, sections were rinsed twice in PBS, permeabilized with $0.3 \%$ Triton X-100 and blocked with 10\% normal donkey serum (Jackson ImmunoResearch) for $1 \mathrm{~h}$. The sections were incubated with the primary antibodies: rabbit anti-GFP (1:200, Cell Signal Technology); rabbit antiCaMKII $\gamma$ (1:200, Abcam) and rabbit anti-NR1 (1:200 Boster) at $4^{\circ} \mathrm{C}$ overnight. Next day, sections were washed with PBS three times and incubated with Alexa Fluor 488 or 594-conjugated donkey anti-rabbit IgG (Jackson ImmunoResearch) for $2 \mathrm{~h}$. After rinsing 3 times in PBS, the sections were visualized and documented with a Leica Observer Microscope (Leica, Germany).

\section{Western blot analysis}

Tissues (L4 L5 spinal cord) and PC-12 cell samples were homogenized in RIPA lysis buffer containing $1 \mathrm{mM}$ phenylmethylsulfonyl fluoride. After centrifugation at $20,000 \times \mathrm{g}$ for $15 \mathrm{~min}$, the supernatant was collected. The protein concentration was determined using the BCA protein Assay Kit (Pierce). Western blot was performed with $30 \mu \mathrm{g}$ of protein extracts and the proteins were separated using 10\% SDS-PAGE at 80 120V for $90 \mathrm{~min}$. After electrophoresis, proteins were transferred to polyvinylidene difluoride (PVDF) membranes (Merck Millipore) at $250 \mathrm{~mA}$ for $50 \mathrm{~min}$. Membranes were blocked with $5 \%$ nonfat milk in TBS buffer containing $0.2 \%$ Tween 20 (TBST) at room temperature for $1 \mathrm{~h}$ to avoid non-specific binding sites. The membranes were probed at $4^{\circ} \mathrm{C}$ overnight with the following primary antibodies: rabbit anti-CaMKII $\gamma$ (1:2000, Abcam); rabbit anti-NR1 (1:1000, Boster) and rabbit anti-GAPDH (1:5000, Abcam). The membranes were washed with TBST three times and incubated with the secondary antibody: peroxidase-conjugated goat anti-rabbit IgG, at room temperature for $1.5 \mathrm{~h}$. After rinsing in TBST three times, the blots were visualized using the enhanced chemiluminescence plus system (Merck Millipore). Western blot data were digitized and analyzed using Image Lab 3.0 (Bio-Rad). The protein density of CaMKII $\gamma$ and NR1 was normalized against the density of GAPDH.

\section{Statistical analysis}

Data are presented as mean \pm standard deviation (SD). The statistical significance was evaluated using Student's $t$-test when comparing with two groups. Multiple groups were compared using one-way or two-way ANOVA followed by Bonferroni multiple comparison tests. All the analyses were performed using Graphpad Prism 5.0 software. $P<0.05$ was considered statistically significant.

\section{ACKNOWLEDGMENTS AND FUNDING}

This study was supported by grants from the National Natural Science Foundation of China (81271244, 81471135 and 81400916) and Social Development Supporting Plan from Department of Science \&Technology of Hunan Province (2014SK3103).

\section{CONFLICTS OF INTEREST}

The authors declare no competing financial interests.

\section{REFERENCES}

1. Benyamin R, Trescot AM, Datta S, Buenaventura R, Adlaka R, Sehgal N, Glaser SE, Vallejo R. Opioid complications and side effects. Pain Physician. 2008; 11:S105-20.

2. He Y, Wang ZJ. Let-7 microRNAs and Opioid Tolerance. Front Genet. 2012; 3:110. doi: 10.3389/fgene.2012.00110.

3. Tapocik JD, Ceniccola K, Mayo CL, Schwandt ML, Solomon M, Wang BD, Luu TV, Olender J, Harrigan T, Maynard TM, Elmer GI, Lee NH. MicroRNAs Are Involved in the Development of Morphine-Induced Analgesic Tolerance and Regulate Functionally Relevant Changes in Serpini1. Front Mol Neurosci. 2016; 9:20. doi: 10.3389/ fnmol.2016.00020.

4. Wang J, Xu W, Zhong T, Song Z, Zou Y, Ding Z, Guo Q, Dong X, Zou W. miR-365 targets beta-arrestin 2 to reverse morphine tolerance in rats. Sci Rep. 2016; 6:38285. doi: 10.1038/srep38285.

5. Kosik KS. The neuronal microRNA system. Nat Rev Neurosci. 2006; 7:911-20. doi: 10.1038/nrn2037.

6. Kim J, Inoue $\mathrm{K}$, Ishii J, Vanti WB, Voronov SV, Murchison E, Hannon G, Abeliovich A. A MicroRNA feedback circuit in midbrain dopamine neurons. Science. 2007; 317:1220-4. doi: 10.1126/science.1140481.

7. Monroig PD, Calin GA. MicroRNA and Epigenetics: Diagnostic and Therapeutic Opportunities. Curr Pathobiol Rep. 2013; 1:43-52. doi: 10.1007/s40139-013-0008-9.

8. Niederberger E, Kynast $\mathrm{K}$, Lotsch J, Geisslinger G. MicroRNAs as new players in the pain game. Pain. 2011; 152:1455-8. doi: 10.1016/j.pain.2011.01.042.

9. Pedersen IM, Cheng G, Wieland S, Volinia S, Croce CM, Chisari FV, David M. Interferon modulation of cellular 
microRNAs as an antiviral mechanism. Nature. 2007; 449:919-22. doi: 10.1038/nature06205.

10. Bali KK, Kuner R. Noncoding RNAs: key molecules in understanding and treating pain. Trends Mol Med. 2014; 20:437-48. doi: 10.1016/j.molmed.2014.05.006.

11. Sun Z, Yu JT, Jiang T, Li MM, Tan L, Zhang Q, Tan L. Genome-wide microRNA profiling of rat hippocampus after status epilepticus induced by amygdala stimulation identifies modulators of neuronal apoptosis. PLoS One. 2013; 8:e78375. doi: 10.1371/journal.pone.0078375.

12. He Y, Yang C, Kirkmire CM, Wang ZJ. Regulation of opioid tolerance by let-7 family microRNA targeting the mu opioid receptor. J Neurosci. 2010; 30:10251-8. doi: 10.1523/ JNEUROSCI.2419-10.2010.

13. Wu Q, Zhang L, Law PY, Wei LN, Loh HH. Long-term morphine treatment decreases the association of muopioid receptor (MOR1) mRNA with polysomes through miRNA23b. Mol Pharmacol. 2009; 75:744-50. doi: 10.1124/mol.108.053462.

14. Li W, He S, Zhou Y, Li Y, Hao J, Zhou X, Wang F, Zhang Y, Huang Z, Li Z, Loh HH, Law PY, Zheng H. Neurod1 modulates opioid antinociceptive tolerance via two distinct mechanisms. Biol Psychiatry. 2014; 76:775-84. doi: 10.1016/j.biopsych.2014.05.013.

15. Qiu S, Feng Y, LeSage G, Zhang Y, Stuart C, He L, Li Y, Caudle Y, Peng Y, Yin D. Chronic morphine-induced microRNA-124 promotes microglial immunosuppression by modulating P65 and TRAF6. J Immunol. 2015; 194:102130. doi: 10.4049/jimmunol.1400106.

16. Lu Z, Xu J, Xu M, Pasternak GW, Pan YX. Morphine regulates expression of mu-opioid receptor MOR-1A, an intron-retention carboxyl terminal splice variant of the muopioid receptor (OPRM1) gene via miR-103/miR-107. Mol Pharmacol. 2014; 85:368-80. doi: 10.1124/mol.113.089292.

17. Xiao WF, Li YS, Lou W, Cai T, Zhang S, Hu XY, Zhang XW, Luo W. MicroRNA-93-5p may participate in the formation of morphine tolerance in bone cancer pain mouse model by targeting Smad5. Oncotarget. 2016; 7:52104-14. doi: 10.18632/oncotarget.10524.

18. Kocerha J, Faghihi MA, Lopez-Toledano MA, Huang J, Ramsey AJ, Caron MG, Sales N, Willoughby D, Elmen J, Hansen HF, Orum H, Kauppinen S, Kenny PJ, et al. MicroRNA-219 modulates NMDA receptor-mediated neurobehavioral dysfunction. Proc Natl Acad Sci U S A. 2009; 106:3507-12. doi: 10.1073/pnas.0805854106.

19. Pan Z, Zhu LJ, Li YQ, Hao LY, Yin C, Yang JX, Guo Y, Zhang S, Hua L, Xue ZY, Zhang H, Cao JL. Epigenetic modification of spinal miR-219 expression regulates chronic inflammation pain by targeting CaMKIIgamma. J Neurosci. 2014; 34:9476-83. doi: 10.1523/JNEUROSCI. 5346-13.2014.

20. Trujillo KA, Akil H. Inhibition of morphine tolerance and dependence by the NMDA receptor antagonist MK- 801 . Science. 1991; 251:85-7.
21. Zheng H, Tang R, Yao Y, Ji Z, Cao Y, Liu Z, Peng F, Wang W, Can D, Xing H, Bu G, Xu H, Zhang YW, et al. MiR-219 Protects Against Seizure in the Kainic Acid Model of Epilepsy. Mol Neurobiol. 2016; 53:1-7. doi: 10.1007/ s12035-014-8981-5.

22. Shimoyama N, Shimoyama M, Davis AM, Monaghan DT, Inturrisi CE. An antisense oligonucleotide to the N-methylD-aspartate (NMDA) subunit NMDAR1 attenuates NMDAinduced nociception, hyperalgesia, and morphine tolerance. J Pharmacol Exp Ther. 2005; 312:834-40. doi: 10.1124/ jpet.104.074856.

23. Tsai RY, Chou KY, Shen CH, Chien CC, Tsai WY, Huang YN, Tao PL, Lin YS, Wong CS. Resveratrol regulates $\mathrm{N}$-methyl-D-aspartate receptor expression and suppresses neuroinflammation in morphine-tolerant rats. Anesth Analg. 2012; 115:944-52. doi: 10.1213/ANE.0b013e31825da0fb.

24. Cheng HY, Papp JW, Varlamova O, Dziema H, Russell B, Curfman JP, Nakazawa T, Shimizu K, Okamura H, Impey S, Obrietan K. microRNA modulation of circadian-clock period and entrainment. Neuron. 2007; 54:813-29. doi: 10.1016/j.neuron.2007.05.017.

25. Dugas JC, Cuellar TL, Scholze A, Ason B, Ibrahim A, Emery B, Zamanian JL, Foo LC, McManus MT, Barres BA. Dicer1 and miR-219 Are required for normal oligodendrocyte differentiation and myelination. Neuron. 2010; 65:597-611. doi: 10.1016/j.neuron.2010.01.027.

26. Li JS, Yao ZX. MicroRNAs: novel regulators of oligodendrocyte differentiation and potential therapeutic targets in demyelination-related diseases. Mol Neurobiol. 2012; 45:200-12. doi: 10.1007/s12035-011-8231-z.

27. Beveridge NJ, Gardiner E, Carroll AP, Tooney PA, Cairns MJ. Schizophrenia is associated with an increase in cortical microRNA biogenesis. Mol Psychiatry. 2010; 15:1176-89. doi: 10.1038/mp.2009.84.

28. Marcuzzo S, Bonanno S, Kapetis D, Barzago C, Cavalcante P, D’Alessandro S, Mantegazza R, Bernasconi P. Up-regulation of neural and cell cycle-related microRNAs in brain of amyotrophic lateral sclerosis mice at late disease stage. Mol Brain. 2015; 8:5. doi: 10.1186/s13041-015-0095-0.

29. Santa-Maria I, Alaniz ME, Renwick N, Cela C, Fulga TA, Van Vactor D, Tuschl T, Clark LN, Shelanski ML, McCabe BD, Crary JF. Dysregulation of microRNA-219 promotes neurodegeneration through post-transcriptional regulation of tau. J Clin Invest. 2015; 125:681-6. doi: 10.1172/JCI78421.

30. Mayford M, Bach ME, Huang YY, Wang L, Hawkins RD, Kandel ER. Control of memory formation through regulated expression of a CaMKII transgene. Science. 1996; 274:1678-83.

31. Giese KP, Fedorov NB, Filipkowski RK, Silva AJ. Autophosphorylation at Thr286 of the alpha calciumcalmodulin kinase II in LTP and learning. Science. 1998; 279:870-3.

32. Hanson PI, Schulman H. Neuronal Ca2+/calmodulindependent protein kinases. Annu Rev Biochem. 1992; 61:559-601. doi: 10.1146/annurev.bi.61.070192.003015. 
33. Lou L, Zhou T, Wang P, Pei G. Modulation of $\mathrm{Ca} 2+/$ calmodulin-dependent protein kinase II activity by acute and chronic morphine administration in rat hippocampus: differential regulation of alpha and beta isoforms. Mol Pharmacol. 1999; 55:557-63.

34. Fan GH, Wang LZ, Qiu HC, Ma L, Pei G. Inhibition of calcium/calmodulin-dependent protein kinase II in rat hippocampus attenuates morphine tolerance and dependence. Mol Pharmacol. 1999; 56:39-45.

35. Kadivar M, Farahmandfar M, Ranjbar FE, Zarrindast MR. Increased calcium/calmodulin-dependent protein kinase II activity by morphine-sensitization in rat hippocampus. Behav Brain Res. 2014; 267:74-82. doi: 10.1016/j. bbr.2014.03.035.

36. Alt A, Nisenbaum ES, Bleakman D, Witkin JM. A role for AMPA receptors in mood disorders. Biochem Pharmacol. 2006; 71:1273-88. doi: 10.1016/j.bcp.2005.12.022.

37. Bleakman D, Alt A, Nisenbaum ES. Glutamate receptors and pain. Semin Cell Dev Biol. 2006; 17:592-604. doi: 10.1016/j.semcdb.2006.10.008.

38. Tai YH, Cheng PY, Tsai RY, Chen YF, Wong CS. Purinergic $\mathrm{P} 2 \mathrm{X}$ receptor regulates $\mathrm{N}$-methyl-D-aspartate receptor expression and synaptic excitatory amino acid concentration in morphine-tolerant rats. Anesthesiology. 2010; 113:1163-75. doi: 10.1097/ALN.0b013e3181f11aa2.

39. Koyuncuoglu H, Nurten A, Yamanturk P, Nurten R. The importance of the number of NMDA receptors in the development of supersensitivity or tolerance to and dependence on morphine. Pharmacol Res. 1999; 39:311-9. doi: 10.1006/phrs.1998.0443.

40. Anderson EM, Del Valle-Pinero AY, Suckow SK, Nolan TA, Neubert JK, Caudle RM. Morphine and MK-801 administration leads to alternative N-methyl-D-aspartate receptor 1 splicing and associated changes in reward seeking behavior and nociception on an operant orofacial assay. Neuroscience. 2012; 214:14-27. doi: 10.1016/j. neuroscience.2012.04.032.

41. Lim G, Wang S, Zeng Q, Sung B, Yang L, Mao J. Expression of spinal NMDA receptor and PKCgamma after chronic morphine is regulated by spinal glucocorticoid receptor. J Neurosci. 2005; 25:11145-54. doi: 10.1523/ JNEUROSCI.3768-05.2005.

42. Hu XM, Cao SB, Zhang HL, Lyu DM, Chen LP, Xu H, Pan ZQ, Shen W. Downregulation of miR-219 enhances brain-derived neurotrophic factor production in mouse dorsal root ganglia to mediate morphine analgesic tolerance by upregulating CaMKIIgamma. Mol Pain. 2016; 12. doi: 10.1177/1744806916666283.

43. Liu M, Kay JC, Shen S, Qiao LY. Endogenous BDNF augments NMDA receptor phosphorylation in the spinal cord via PLCgamma, PKC, and PI3K/Akt pathways during colitis. J Neuroinflammation. 2015; 12:151. doi: 10.1186/ s12974-015-0371-z.

44. Wang LN, Yang JP, Ji FH, Zhan Y, Jin XH, Xu QN, Wang XY, Zuo JL. Brain-derived neurotrophic factor modulates N-methyl-D-aspartate receptor activation in a rat model of cancer-induced bone pain. J Neurosci Res. 2012; 90:1249-60. doi: 10.1002/jnr.22815.

45. Park H, Popescu A, Poo MM. Essential role of presynaptic NMDA receptors in activity-dependent BDNF secretion and corticostriatal LTP. Neuron. 2014; 84:1009-22. doi: 10.1016/j.neuron.2014.10.045.

46. Hildebrand ME, Xu J, Dedek A, Li Y, Sengar AS, Beggs S, Lombroso PJ, Salter MW. Potentiation of Synaptic GluN2B NMDAR Currents by Fyn Kinase Is Gated through BDNFMediated Disinhibition in Spinal Pain Processing. Cell Rep. 2016; 17:2753-65. doi: 10.1016/j.celrep.2016.11.024.

47. Matsushita Y, Omotuyi IO, Mukae T, Ueda H. Microglia activation precedes the anti-opioid BDNF and NMDA receptor mechanisms underlying morphine analgesic tolerance. Curr Pharm Des. 2013; 19:7355-61.

48. Rao SA, Arimappamagan A, Pandey P, Santosh V, Hegde AS, Chandramouli BA, Somasundaram K. miR-219-5p inhibits receptor tyrosine kinase pathway by targeting EGFR in glioblastoma. PLoS One. 2013; 8:e63164. doi: 10.1371/journal.pone.0063164.

49. Cheng J, Deng R, Zhang P, Wu C, Wu K, Shi L, Liu X, Bai J, Deng M, Shuai X, Gao J, Wang G, Tao K. miR219-5p plays a tumor suppressive role in colon cancer by targeting oncogene Sall4. Oncol Rep. 2015; 34:1923-32. doi: 10.3892/or.2015.4168.

50. Zimmermann M. Ethical guidelines for investigations of experimental pain in conscious animals. Pain. 1983; 16:109-10.

51. Yaksh TL, Kohl RL, Rudy TA. Induction of tolerance and withdrawal in rats receiving morphine in the spinal subarachnoid space. Eur J Pharmacol. 1977; 42:275-84.

52. Song Z, Zou W, Liu C, Guo Q. Gene knockdown with lentiviral vector-mediated intrathecal RNA interference of protein kinase $\mathrm{C}$ gamma reverses chronic morphine tolerance in rats. J Gene Med. 2010; 12:873-80. doi: 10.1002/jgm.1514.

53. Yang $\mathrm{CH}$, Huang HW, Chen KH, Chen YS, SheenChen SM, Lin CR. Antinociceptive potentiation and attenuation of tolerance by intrathecal beta-arrestin 2 small interfering RNA in rats. Br J Anaesth. 2011; 107:774-81. doi: 10.1093/bja/aer291.

54. Dirig DM, Salami A, Rathbun ML, Ozaki GT, Yaksh TL. Characterization of variables defining hindpaw withdrawal latency evoked by radiant thermal stimuli. J Neurosci Methods. 1997; 76:183-91.

55. Zou W, Song Z, Guo Q, Liu C, Zhang Z, Zhang Y. Intrathecal lentiviral-mediated RNA interference targeting PKCgamma attenuates chronic constriction injury-induced neuropathic pain in rats. Hum Gene Ther. 2011; 22:465-75. doi: 10.1089/hum.2010.207.

56. Pfaffl MW. A new mathematical model for relative quantification in real-time RT-PCR. Nucleic Acids Res. 2001; 29:e45. 